\title{
CONTRIBUIÇÕES PARA UMA HISTÓRIA DA EDUCAÇÃO MATEMÁTICA EM SANTA CATARINA: A MODERNIZAÇÃO DA ARITMÉTICA NA REFORMA ORESTES GUIMARÃES (1910-1914) \\ DOI: http://dx.doi.org/10.1590/2236-3459/59428
}

\author{
David Antonio da Costa \\ Universidade Federal de Santa Catarina, Brasil. \\ Thuysa Schlichting de Souza \\ Universidade Federal de Santa Catarina, Brasil.
}

$\cos 80$

\section{Resumo}

No âmbito deste artigo tem-se por objetivo compreender a inclusão e organização da matéria Aritmética nos programas de ensino dos grupos escolares de Santa Catarina durante os primeiros anos da reforma Orestes Guimarães. O período privilegiado na investigação é marcado pelo afloramento dos discursos da pedagogia moderna no Brasil. Assim, as discussões focalizam as implicações de uma educação renovada e moderna nas prescrições da matéria em questão. A análise histórica toma como fonte de pesquisa os documentos escolares normativos. $O$ estudo permitiu o delineamento de um panorama educacional em que a matriz pedagógica do ensino intuitivo, alicerçada pela organização graduada dos estudos seriados, caracterizou uma nova formatação para o ensino da Aritmética nos grupos escolares catarinenses.

Palavras-chave: Aritmética, grupos escolares, método intuitivo, educação matemática.

\section{CONTRIBUTIONS TO A HISTORY OF MATHEMATICS EDUCATION IN \\ SANTA CATARINA: ARITHMETIC MODERNIZATION DURING ORESTES GUIMARÃES REFORM (1910-1914)}

\begin{abstract}
This article aims to understand the arithmetic's inclusion and organization in School Groups' curriculum during the early years of Orestes Guimarães Reform in Santa Catarina, Brazil. This research focuses on the period marked by Modern Pedagogy hegemony in the country, therefore our analysis considers the implications of a renewed and modern education in arithmetic prescriptions. This historical analysis adopts the documents which regulated the reform as research's source. The study allowed to design an educational panorama where the pedagogical
\end{abstract}


matrix of intuitive teaching, based on serial graded studies, characterized a new standard for arithmetic teaching in Santa Catarina School Groups.

Key-words: Arithmetic, school groups, intuitive method, mathematics education.

\section{APORTES PARA UNA HISTORIA DE EDUCACIÓN MATEMÁTICA EN SANTA CATARINA: LA MODERNIZACIÓN DE LA ARITMÉTICA EN EL TIEMPO DE LA REFORMA ORESTES GUIMARAES (1910-1914)}

\section{Resumen}

El artículo tiene como objetivo comprender la inclusión y la organización de la aritmética en los programas educativos de los Grupos escolares en Santa Catarina durante los primeros años de la Reforma Orestes Guimarães. El período privilegiado en la investigación se caracteriza por afloramientos de los discursos de la pedagogía moderna en Brasil, por lo que las discusiones se centran en las consecuencias de una educación renovada y moderna en las prescripciones de la materia aritmética. El análisis adopta los documentos normativos de las escuelas como una fuente de investigación. El estudio describe un panorama educativo marcado por la enseñanza intuitiva que contó con un nuevo formato para la enseñanza de la aritmética en los Grupos Escolares. Palabras-clave: Aritmética, escuela primaria, método intuitivo, educación matemática.

\section{LES CONTRIBUTIONS POUR UNE HISTOIRE DE L'ÉDUCATION DE MATHÉMATIQUE DANS L'ÉTAT DE SANTA CATARINA: LA MODERNISATION DE L'ARITHMÉTIQUE PENDANT LA RÉFORME ORESTES GUIMARÃES (1910-1914)}

\section{Résumé}

Cet article vise à comprendre l'inclusion et l'organisation de l'arithmétique dans le programme des Groupes Scolaires au cours des premières années de la réforme Oreste Guimarães à Santa Catarina, Brésil. Cette recherche porte sur la période marquée par l'hégémonie de la pédagogie moderne dans le pays, donc notre analyse examine les implications d'une éducation renouvelée et moderne dans les prescriptions arithmétiques. L'analyse historique prend comme source de recherche des documents scolaires normative. L'étude a permis de concevoir un panorama éducatif où la matrice pédagogique de l'enseignement intuitive, basée sur des études graduées en série, caractérisé une nouvelle norme pour l'enseignement de l'arithmétique aux les Groupes Scolaires dans l' État de Santa Catarina.

Mots-clé: l'arithmétique, les groupes scolaires, le méthode intuitive, l'enseignement de mathématique. 


\section{Introdução}

m tempos de discussão de uma base nacional comum curricular para se determinar os conhecimentos e as habilidades essenciais aos alunos das escolas brasileiras, os estudos que objetivam compreender as transformações que os saberes escolares sofreram ao longo do tempo tornam-se primordiais. Quando se trata de reorganizar as finalidades e os componentes curriculares de uma disciplina escolar é necessário refletir e rememorar sobre o lugar ocupado pelas tradições pedagógicas na cultura escolar.

Nesse sentido, a história da educação matemática se configura em importante espaço de produção de pesquisas que permitem a "construção de ultrapassagens de relações ingênuas, míticas, românticas e memorialísticas sobre as práticas do ensino de matemática realizadas no passado", como bem salienta Leme da Silva e Valente (2013, p. 180). Pelo diálogo com os referenciais teóricos da História, o olhar do pesquisador da história da educação matemática volta-se para as transformações que ocorreram nos saberes matemáticos, e nas disciplinas que os institucionalizaram, levando em conta as mudanças das modalidades de ensino e as razões para tais modificações. Mais do que o estudo dos conteúdos ensinados, almeja-se compreender suas relações com os métodos e as práticas de ensino.

Considerando que o artigo está inserido nesta perspectiva, objetivamos compreender a constituição e os movimentos de transformação da matemática escolar nos anos iniciais. Em específico focalizaremos a matéria de Aritmética nas escolas primárias graduadas, os grupos escolares, em Santa Catarina, nos primeiros anos do período republicano, quando "a escola popular foi elevada à condição de redentora da nação e de instrumento de modernização por excelência" (Souza, 2000, p. 12).

Cabe salientar que os saberes matemáticos contemplados na matéria de Aritmética no ensino primário tratam do conhecimento dos números - naturais e racionais - e das operações que se podem realizar com os mesmos, dos algarismos romanos, da regra de três simples, do sistema de pesos e medidas, dos juros, da porcentagem e de outros aprendizados de cálculo. Ademais, a palavra Aritmética é empregada no sentido de uma Aritmética escolar que, mais do que o conceito matemático do corpo de símbolos e suas operações, é resultante de práticas que se realizam no interior da escola, "de um diálogo secular entre os professores e seus alunos, um código entre duas gerações, que lenta e minuciosamente, é elaborado em conjunto, de modo que uma das gerações possa transmitir à outra, uma cultura determinada" (Leme da Silva; Valente, 2013, p. 185).

Este estudo privilegia, ainda, os grupos escolares como local de investigação, devido à importância destas instituições para o ensino primário brasileiro, e particularmente catarinense, ao ocasionar mudanças significativas na estrutura curricular e disciplinar da escola pública. $O$ recorte temporal proposto abrange uma importante reforma da instrução pública de Santa Catarina que, em 1910, estabeleceu a implantação dos grupos escolares no Estado e inaugurou um novo modelo político-administrativo de educação pública. Por tratar-se de um momento que contempla diversas modificações no cenário educacional catarinense, especialmente no que diz respeito às reformas curriculares - quando ficam evidenciadas novas propostas de ensino -, este se constitui em período favorável para investigações historiográficas (Chervel, 1990). 
A análise aqui proposta considera o papel histórico da escola para a produção dos saberes escolares, como André Chervel (1990) e Julia (2001) em seus trabalhos relativos à história das disciplinas escolares ${ }^{1}$. Assim, pesquisar os saberes elementares matemáticos buscando o entendimento das práticas escolares e de como foram pensados e organizados oficialmente as concepções e os instrumentos pedagógicos indicados nos documentos oficiais, é essencial para uma escrita da história da matemática escolar nesta perspectiva. Entretanto, esta investigação está inserida no âmbito das intenções e das determinações, as quais podem nos informar das finalidades teóricas de ensino, ou finalidades de objetivo, que são distintas das finalidades reais (Chervel, 1990).

Definimos, dessa forma, os programas de ensino para os grupos escolares catarinenses de 1911 e 1914, que vigoraram no período proposto, como corpus fundamental de estudo, além das principais legislações que buscavam, de alguma forma, modificar o ensino nestas instituições. Como o período em questão foi marcado pelo afloramento dos discursos da Pedagogia Moderna em vários Estados brasileiros, inclusive em Santa Catarina, pretendemos compreender a inclusão e a organização da matéria de Aritmética nos programas de ensino citados anteriormente, focalizando as implicações de uma educação renovada e moderna para as suas prescrições.

Convêm destacar, conforme Souza (2000) aponta em seus estudos, que a legislação deve ser entendida como uma prática ordenadora das relações sociais. Seguindo esta ideia, buscaremos analisar os programas que consubstanciaram a reforma do ensino primário como uma forma discursiva de intervenção social e de produção de práticas.

\section{Um breve diálogo com a historiografia da educação}

Estudos históricos sobre as transformações no ensino primário brasileiro indicam que, ao fim do período imperial, surgiram as primeiras discussões acerca da hegemonia da pedagogia moderna em relação à pedagogia tradicional no país. Em consonância com os debates educacionais em âmbito internacional, os intelectuais da educação brasileira almejavam romper com os antigos métodos e práticas da escola primária fundamentados principalmente no ensino do ler, escrever e contar, em práticas dogmáticas e na memorização - e renovar o programa escolar adequando-os aos princípios dos modernos processos pedagógicos. Essa adequação pedagógica efetivouse, principalmente, por meio do método de ensino intuitivo (Souza, 2000; Teive, 2014).

Tal método pressupunha que o conhecimento tem início na operação dos sentidos sobre o mundo externo. De matriz epistemológica empirista, fundamentava-se na ideia de que o meio necessário para a aquisição dos conhecimentos é a intuição, pela atividade da criança e da experiência sensorial. Respaldado, especialmente, nas ideias de Pestalozzi, defendia uma abordagem indutiva, iniciando do particular para o geral, do concreto para o abstrato, do conhecido para o desconhecido, das coisas para as palavras.

\footnotetext{
${ }^{1} \mathrm{O}$ foco do trabalho recai sobre os ensinos no curso primário, por isso mantemos distância relativa ao que toca à questão disciplinar. Empregaremos a palavra matéria em referência ao conjunto de saberes a serem ensinados nos grupos escolares de Santa Catarina. Fundamentados nos estudos de Chervel (1990), consideramos o papel histórico da escola na produção dos saberes escolares em termos das matérias de ensino.
} 
Assim, se as transformações no curso primário engendraram novas práticas e métodos para o ensino, a pedagogia moderna requereu a renovação do trabalho docente, a reorganização da escola primária e a criação de materiais didáticos mais adequados às novas concepções pedagógicas. O Estado de São Paulo destaca-se neste cenário por ter sido uma das primeiras unidades federativas a implantar reformas segundo os postulados da pedagogia moderna, tornando-se pioneiro na implantação de um sistema público de ensino primário gratuito.

Outra inovação da reforma paulista foi a instituição das escolas primárias graduadas, denominadas de grupos escolares, em 1893, as quais serviram de modelo para os demais Estados brasileiros na ordenação do ensino primário ${ }^{2}$. Santa Catarina, por exemplo, reformou o sistema de instrução pública a partir da experiência paulista em 1910, estruturando um sistema centralizado e hierarquizado por meio de rígidos dispositivos normativos, como regulamentos, programas e regimentos, instituídos por lei. Assim, na reforma Orestes Guimarães ${ }^{3}$, ocorreram mudanças significativas no ensino público catarinense tanto na sua estrutura, quanto nos processos pedagógicos.

Seguindo o modelo implantado em São Paulo, o professor Orestes Guimarães acreditava que a reforma deveria ter como base a reforma dos mestres e a reforma do método de ensino (Teive, 2008). Dessa forma, as marcas da Pedagogia Moderna podem ser verificadas em vários documentos normativos expedidos para a regulamentação da reforma, bem como nos textos que assinalam a atuação dos governantes no período de seu mandato, conforme observamos na sinopse apresentada pelo governador Vidal Ramos ao Congresso Representativo do Estado:

Hoje ninguem mais se atreve a defender os methodos de ensino, que, como os que ainda vigoravam entre nós, tem seu fundamento unico e exclusivo na memoria. Esse facto bastava por si só a justificar a necessidade de uma radical reforma do nosso aparelho escolar, de modo a harmoniza-lo com as exigências crescentes da vida social contemporanea e com os incontroversos ensinamentos da pedagogia moderna. (Santa Catarina, 1914c, p. 135)

No trecho destacado o discurso de Vidal Ramos exalta o modelo pedagógico proveniente da Pedagogia Moderna em detrimento do ensino tradicional, a velha pedagogia baseada na memorização. Corroborando com nossa discussão, Valente (2013)

2 Podemos citar os Estados de Mato Grosso (Sá, 2006), Minas Gerais (Faria Filho, 1996; Araújo, 2006), Paraná (Bencostta, 2006), Piauí (Lopes, 2006), Santa Catarina (Gaspar da Silva, 2006; Teive, 2008), entre outros.

${ }^{3}$ A reforma recebeu este nome pela historiografia catarinense, pois o professor paulista Orestes Guimarães foi quem conduziu as mudanças na educação pública em Santa Catarina sob o cargo de inspetor-geral da Instrução Pública. Ver Teive (2008). 
afirma que a representação ${ }^{4}$ do ensino tradicional emerge e consolida-se, sobretudo, na época de Rui Barbosa como um ensino livresco e de repetição por processos mecânicos. Em Santa Catarina Orestes Guimarães foi quem defendeu e disseminou o novo movimento pedagógico nos grupos escolares, utilizando do contato direto e pessoal para a difusão do método de ensino intuitivo nas escolas do Estado (Fiori, 1991).

Tendo em vista a importância dada ao método intuitivo na Reforma Orestes Guimarães e focalizando as matérias escolares que foram instituídas para os programas dos grupos escolares, surgem alguns questionamentos: como o método de ensino intuitivo modificou a cultura escolar dos grupos escolares catarinenses? Como esse método influenciou as prescrições para a matéria de Aritmética nessas instituições? Que representação da Aritmética pode ser vista e lida nos programas de ensino para os grupos escolares de 1911 e 1914, tendo por matriz de ensino o método intuitivo?

\section{Os primeiros suspiros de uma Aritmética escolar em Santa Catarina}

A escola nem sempre foi seriada e organizada em graus sucessivos de ensino. $O$ curso primário, por exemplo, aqui entendido como o início do processo educativo, a base sobre a qual sustentam os demais alicerces da estrutura da educação escolarizada, foi modificado e estruturado de diversas formas ao longo do tempo. Logo, as matérias escolares que estão a serviço das finalidades educativas também são alteradas nesse processo.

Ao analisar como se configurou, nos primeiros tempos de Império brasileiro, o ensino de Matemática na chamada escola de ler, escrever e contar, Valente (2006) indica que a matemática consagrada a ser ensinada no primário foi, sobretudo, as quatro operações fundamentais da Aritmética. O contar era ligado diretamente ao aprendizado das tabuadas que sintetizam as quatro operações básicas: soma, subtração, multiplicação e divisão.

Com a proclamação da República e o advento dos grupos escolares nos Estados brasileiros, surgiu um novo tempo de renovação pedagógica, da modernização do ensino mediante o método intuitivo. Isso implicou diretamente numa alteração da forma consagrada de tratar a Aritmética na antiga escola de ler, escrever e contar. Compreendemos, assim, que as transformações da aritmética escolar frente às novas concepções pedagógicas ao início do período republicano podem ser lidas e vistas nos documentos oficiais que embasaram a reforma da instrução pública catarinense em 1910.

Vale ressaltar que os grupos escolares inauguraram um espaço educacional próprio e um modelo de cultura escolar específico, o que exigiu a criação de novos dispositivos de regulamentação destas instituições escolares. Nesse sentido, o regimento interno e os programas de ensino dos grupos escolares tornam-se essenciais para a consolidação da

\footnotetext{
${ }^{4}$ Roger Chartier (1990) realizou estudos sobre a história cultural e o papel das representações. Em seus trabalhos compreende por representação uma noção que "permite articular três modalidades da relação com o mundo social: em primeiro lugar, o trabalho de classificação e de delimitação que produz as configurações intelectuais múltiplas, através das quais a realidade é contraditoriamente construída pelos diferentes grupos; seguidamente, as práticas que visam [a] fazer reconhecer uma identidade social, exibir uma maneira própria de estar no mundo, significar simbolicamente um estatuto e uma posição; por fim, as formas institucionais e objetivas graças às quais uns "representantes" (instâncias coletivas ou pessoa singulares) marcam de forma visível e perpetuada a existência do grupo, da classe ou da comunidade" (Chartier, 1990, p. 23).
} 
reforma da instrução pública ao determinarem os conteúdos a serem ensinados nas matérias e as diretrizes acerca dos métodos de ensino e procedimentos didáticos que deveriam ser praticados nos grupos escolares, respectivamente.

Foi o decreto n. 587, de 22 de abril de 1911, que aprovou o programa de ensino dos grupos escolares e escolas isoladas em Santa Catarina para atender a reforma no Estado. A responsabilidade por sua idealização foi do professor Orestes Guimarães que, no cargo de diretor geral da instrução pública, tinha como atribuições apresentar e criar regulamentos, regimentos, programas e horários para o novo aparelhamento escolar (Teive; Dallabrida, 2011). No que diz respeito aos grupos escolares o programa foi dividido em quatro anos e os conteúdos prescritos categorizados em matérias.

Segundo Hoeller e Souza (2009), a distribuição dos conteúdos no programa permitia a gradação do ensino e também visava a normatizar, caso ocorresse, o fluxo dos alunos de uma escola para outra. Ademais, a seriação do ensino possibilitava uma homogeneização dos estudantes em cada classe, de forma que estes estivessem dentro de uma mesma faixa etária e de um mesmo grau de desenvolvimento escolar, e ainda os preparava para a inserção em graus mais elevados de escolarização. Nas próprias palavras de Orestes Guimarães, o curso superior seria o "desenvolvimento do inferior, ou aquele corolário deste" (Guimarães, 1913, p. 35).

Relativamente aos saberes matemáticos identificamos as matérias de Aritmética, Geometria e Desenho, contempladas em todos os anos do curso primário. Para a Aritmética os aspectos metodológicos são indicados superficialmente, sendo um programa de caráter mais descritivo que visava, principalmente, ao estabelecimento dos conteúdos de ensino. Podemos inferir que isto ocorreu, pois, os documentos normativos de 1911 foram escritos com o intuito de instaurar uma cultura escolar própria dos grupos escolares e, desta forma, coube ao programa estabelecer os conteúdos básicos para a matéria de Aritmética e, ao regimento, indicar seus aspectos metodológicos.

Observamos ainda, por meio da análise do programa, que os conteúdos se desenvolvem pelo aumento crescente de dificuldade e são aprofundados progressivamente, de maneira que os conhecimentos exigidos nos anos mais avançados dependam essencialmente daqueles aprendidos nos anteriores. Por exemplo: indica-se para o primeiro ano que a criança deva aprender a ler e escrever os números, seguindo com a aprendizagem das quatro operações básicas da forma mais simples, apenas com os números naturais até 100. A partir do segundo ano,já encontramos elementos do ensino de frações, pois são prescritas as quatro operações "inclusive conhecimento de $1 / 2$, 1/3, 1/4, etc." (Santa Catarina, 1911a, p. 5). No entanto, o conteúdo sobre frações deve ser ampliado no terceiro ano, por meio da aprendizagem das frações decimais. Dessa forma, já é possível estender o estudo do sistema métrico, iniciado no segundo ano.

A constatação anterior vai ao encontro de uma das principais ideias que o inspetor Orestes Guimarães defendia para as escolas primárias catarinenses: o sistema didático no Estado deveria ser baseado no "princípio pedagógico de que o ensino deve ser lento e progressivo" (Guimarães, 1913, p. 36).

Outra questão que merece ser destacada trata-se da recomendação para o uso de materiais concretos, como os tornos de sapateiros e tabuinhas, para o ensino dos rudimentos das primeiras operações, e os exercícios e problemas práticos indicados para 
os últimos anos de escolarização. É importante salientarmos que estas indicações estão em conformidade com as prescrições estabelecidas no Regimento interno dos grupos escolares:

Art. 6. As licções sobre as materias de qualquer dos annos do curso, deverão, de acordo com o programma adoptado, ser mais praticas e concretas do que theoricas e abstractas, e encaminhadas de modo que as faculdades das creanças sejam incitadas a um desenvolvimento gradual e harmonico. § unico. Cumpre que o professor tenha em vista desenvolver a faculdade de observação, e para isso, empregue processos intuitivos. (Santa Catarina, 1911b, p. 4)

O ensino intuitivo, concreto, gradual, com ordenamento lógico das ideias e conteúdos - conforme observados nas prescrições para a matéria de Aritmética no Programa e nas determinações do Regimento interno - segue a fórmula das lições de coisas ou do método intuitivo. Valdemarin (1998, p. 68) afirma que este método trazia a proposta de combater o "caráter abstrato e pouco utilitário da instrução", investindo no "concreto, racional e ativo, denominado ensino pelo aspecto, lições de coisas ou ensino intuitivo". Assim, o novo método negava o ensino pautado na pedagogia tradicional, a qual era associada pelos reformadores catarinenses ao fracasso da instrução pública no Estado:

\begin{abstract}
Instrucção Publica
Esse magno problema constituiu preoccupação primordial do meu governo, que tudo envidou para que Santa Catharina abandonasse o nível reconhecidamente inferior em que a esse respeito se conservava no seio da Federação. $O$ conhecimento que a minha anterior administração me dera do assumpto no Estado [...] produziram-me a convicção de que o ensino popular em Santa Catharina, enterreirado no ambito estreito de velhos moldes e circumscripto á formula carunchada e gasta do ler, escrever e contar, não só contrastava com as nitidas exigências da democracia, [...] senão também estava muito longe de preencher os fins a que se destina, desenvolvendo harmonicamente as faculdades physicas, intellectuaese e moraes. (Ramos, 1914, p. 134)
\end{abstract}

As palavras de Vidal Ramos demonstram, ainda, uma representação do passado do ensino primário catarinense profundamente negativa e, também, caracterizam um discurso educacional afinado ao projeto republicano de instrução das camadas populares. Nóbrega (2003) corrobora com esta discussão ao afirmar que, durante o regime republicano, a retórica educacional oficial procurou associar as reformas do ensino público à constituição ou ao fortalecimento da nacionalidade, da cidadania e da democracia, relacionando-os ao novo e ao moderno, representados pelo novo regime, em oposição ao velho e ineficaz, associados às instituições do regime imperial. Dessa maneira a Pedagogia Moderna, da qual o método de ensino intuitivo e as lições de coisas são os principais ícones, foi ressaltada como configuradora do novo modelo de instrução popular.

Para romper com o modo tradicional de ensinar Aritmética os documentos normativos estabeleceram uma nova forma de tratar esta matéria nos grupos escolares catarinenses, principalmente nos dois primeiros anos do curso primário. Como vimos no programa e no regimento interno de 1911, buscou-se eliminar o ensino abstrato da 
Aritmética, baseado principalmente na memorização, e institui-se, em seu lugar, o ensino concreto, fundamentado nos sentidos e percepções. De fato, segundo Teive (2008), os pressupostos do método intuitivo são a ênfase ao empírico, à observação, ao ver, ao tocar e ao sentir. São fundamentados no princípio de que o conhecimento tem início na operação dos sentidos sobre o mundo externo, os quais produzem as primeiras sensações e percepções sobre os objetos e fatos.

Após alguns anos vigorando no Estado as proposições advindas da reforma educacional de 1910 foram alteradas e os "textos normativos foram avaliados e reestruturados, ganhando formato bem mais elaborado" (Teive; Dallabrida, 2011, p. 121). Assim, a lei n. 967, de 22 de agosto de 1913, autorizou o poder executivo a rever os regulamentos da instrução pública vigentes no Estado, sendo o decreto n. 796, de 2 de maio de 1914, responsável pela instituição do novo programa de ensino dos grupos escolares. Já o Regimento interno, que também foi revisado, determinou aos diretores e professores a obrigatoriedade em cumprir o programa em toda a sua "inteireza, não sendo permitido supprimir partes, saltear ou inverter a ordem em que se acharem as partes" (Santa Catarina, 1914b, p.13).

Destacamos, ainda, que os reformadores catarinenses exigiam a formação na escola normal para os professores que iriam lecionar nos grupos escolares. Assim, dentro do conjunto proposto pela reforma, a escola normal deveria formar o professorado na pedagogia moderna, pois seriam eles responsáveis diretos pela instauração, nas formas escolares recém-inauguradas, da nova cultura escolar, alicerçada nos pressupostos do novo método de ensino (Teive, 2008). Logo, como o curso normal tinha duração de três anos, os primeiros docentes formados nessa nova perspectiva passaram a atuar nas escolas a partir do ano de 1914.

\section{Emergência de uma aritmética escolar intuitiva no programa de 1914}

Sobre as modificações constatadas no programa de 1914 , temos a inclusão de algumas matérias em detrimento de outras, além de mudanças na distribuição das matérias por ano. Por exemplo, a matéria de Linguagem, incluída para todos os anos no programa anterior, foi dividida em duas matérias no programa de 1914: Linguagem Oral e Linguagem Escrita. Já a matéria de Ciências Físicas e Naturais do programa de 1911 é extinta do novo programa e, em seu lugar, temos a inclusão de Botânica, Zoologia, Física e Química, para os três últimos anos.

O novo programa apresenta, ainda, os conteúdos a serem ensinados em cada ano escolar de forma mais detalhada que o anterior, explicitando os passos metodológicos e descrevendo as fases de ensino minuciosamente. Precisamente à matéria de Aritmética, os conteúdos indicados no programa de 1914 são basicamente os mesmos do programa de 1911. No entanto, há uma notável diferença: a inclusão de notas dirigidas aos professores, para o primeiro e segundo ano, e da inserção de alguns exemplos de problemas, que deveriam ser trabalhados pelo professor, com descrição detalhada nos dois primeiros anos, como destacado no excerto abaixo:

O professor muna-se de collecções de objetos iguaes, bem sensiveis á vista dos alumnos, pelas suas dimensões - lugar em que estejam colocados - e estabeleça palestras encaminhando o ensino, de modo que, 
apresentada uma collecção - ora de tres, ora de quatro, de seis, sete, etc., dez objetos - eles divulguem e digam quantos são, ex:

- Paulo, quantas taboinhas tenho aqui?

- Quatro taboinhas.

- (Retirando as mãos atraz das costas e apresentando a coleção augmentada).

- E agora?

- Nove taboinhas.

- E agora, Julio?

- Dez taboinhas

(Pratiquem bem estes exercicios variando o emprego das quantidades das collecções de objetos e augmentando-as paulatinamente até 20). (Santa Catarina, 1914a, p. 21)

As orientações evidenciadas anteriormente apresentam o caminho pelo qual a ideia de quantidade tende a ser formada. Nas concepções do método intuitivo não se inicia o ensino dos números mostrando para a criança os algarismos indo-arábicos, pelo contrário, a experiência concreta, perceptiva e sensível deve conduzir o ensino da ideia de número. Por meio de palestras encaminhadas pelos professores e do contato com objetos disponibilizados, o sentido da observação seria despertado no aluno para que este descobrisse por si mesmo os primeiros conceitos do número.

Notamos, assim, que as indicações são voltadas às ações do professor, para aquilo que o docente deveria ou não realizar nas fases educativas, ou seja, as práticas de ensino permanecem centrado no protagonismo do professor e não no da criança. Compreendemos que isso acontece, pois, o método intuitivo baseia-se no ensino ativo, o qual considera que os saberes escolares devem ser trazidos ao aluno mediante a atividade dos docentes na disponibilização de imagens e objetos relativos à aula.

O Regimento interno dos grupos escolares de 1914 também é claro ao instituir o método intuitivo como orientador para o ensino de Aritmética:

Art. 52. - O ensino de arithmetica terá em vista desenvolver o raciocinio, ministrar noções necessárias á vida pratica. As denominações e as definições, succintas, dos diversos assumptos, e que se façam necessarias, serão deduzidas dos exemplos, pelos alunos. (Santa Catarina, 1914b, p.18)

Os conteúdos de Aritmética ainda se constituíam em importante instrumento educativo. Os professores eram prevenidos para o fato de que, em geral, as crianças maiores de seis anos ingressavam nas escolas com noções básicas quantos aos cinco primeiros números, mas desconhecendo as possibilidades de combinações e operações: somar, diminuir, multiplicar e dividir. Seguindo as premissas do método intuitivo, orientava-se que não se deveria ter pressa "pois, o ensino desta disciplina, por sua natureza, deve ser methodizado de modo que desenvolva sobretudo o raciocínio, suggira e cultive o espírito de dedução. É pois uma phase educativa" (Santa Catarina, 1914b, p. 24).

A classificação dos alunos aparece como novo dispositivo para a organização pedagógica dos grupos escolares baseada na divisão dos estudantes em seções por nível de desempenho. Estas observações surgem, neste programa, especificamente para o primeiro ano durante as prescrições para a matéria de leitura, quando, por meio da 
atividade de leitura da cartilha, o professor deveria dividir a classe em três seções (A, B e C), conforme aproveitamento dos alunos. Apesar da divisão da turma se constituir durante a leitura, esta permanece em algumas atividades de Aritmética, as quais deveriam ser realizadas apenas para os alunos da seção $A$, a dos mais ativos.

Cabe ressaltar, ainda, que o artigo 45 do Regimento interno dos grupos escolares determina que "os methodos e os processos de ensino serão, maximé nos primeiros anos, os mais intuitivos" (Santa Catarina, 1914b, p. 15). Assim, percebemos que, para a matéria de Aritmética a partir do terceiro ano, não são apresentadas as descrições de ordem metodológica em detalhes e os conteúdos passam a ter um caráter mais abstrato e complexo. Já são abordados os estudos das frações, porcentagem, juros simples, divisores, números primos, sistema decimal e métrico, etc., embora, em alguns momentos, ainda se valorize o conhecimento prático, como exercícios de medição de alturas pela sombra.

Salientamos que Orestes Guimarães esteve no comando da instrução pública catarinense de 1911 a 1918 - quando foi confiado ao cargo de inspetor federal das escolas subvencionadas pela União - mantendo controle constante sobre as novas formas de escolarização por ele instituídas. Por essa razão não deixa de ser sintomático o fato de que após a sua saída da inspeção geral do ensino muitas das antigas práticas escolares fossem reaparecendo (Teive, 2008).

A análise nos permitiu compreender como a matéria de Aritmética foi incluída e organizada para os grupos escolares catarinenses durante a reforma Orestes Guimarães, momento em que as concepções da pedagogia moderna estavam em voga no Estado. No entanto, para ultrapassar o modo tradicional de ensinar Aritmética atendendo aos fundamentos do método intuitivo, era preciso prescrever os materiais didáticos que melhor se adequassem ao novo método. Quais eram, então, estes materiais?

\section{Os materiais didáticos para uma aritmética escolar em tempos de ensino intuitivo}

A análise realizada nos programas de ensino dos grupos escolares de Santa Catarina de 1911 e 1914 mostrou que, durante a reforma Orestes Guimarães, havia uma forte presença das concepções do método intuitivo nas indicações para a matéria de Aritmética. A recomendação do uso de materiais concretos, dos problemas e exercícios relacionados ao sistema métrico e monetário, e da aprendizagem gradual dos números no decorrer dos anos são apenas alguns exemplos que indicam tal influência.

Neste contexto, a renovação pedagógica empreendida pela reforma, a qual buscava romper com o caráter abstrato e pouco utilitário da instrução pública no Estado, além de prescrever um novo método de ensino, determinou a utilização de novos materiais didáticos, mais adequados ao método de ensino intuitivo. No caso da Aritmética os materiais difundidos para uso em classe neste período compreendem os objetos concretos, como tornos de sapateiros e taboinhas (Santa Catarina, 1911a) e os quadros de Parker (Santa Catarina, 1914a), em substituição aos livros de textos para memorização.

De acordo com Valente (2013), os quadros de Parker integram um conjunto de gravuras organizado e técnico, cuja finalidade é facilitar a condução metódica do ensino pelo professor. As gravuras são acompanhadas de orientações e instruções aos docentes 
indicando a maneira de utilizá-las para o ensino dos conteúdos aritméticos. Exemplos e perguntas são recomendados para a condução das aulas e para o avanço na leitura de cada um dos quadros. Sob a égide das lições de coisas - da pedagogia do olhar, ver, observar -, é natural que apenas o professor faça uso desse objeto por meio da sua exposição. Em síntese: os quadros de Parker representam a maneira de abordar o ensino de Aritmética de forma ativa, na moderna pedagogia do ensino primário.

Orestes Guimarães foi defensor e difusor da utilização desse material nos grupos escolares catarinenses. Segundo o professor paulista, ainda quando responsável pela diretoria do Colégio Municipal de Joinville ${ }^{5}$, os quadros de Parker são um "excelente processo de cálculo mental" que poupa tempo ao professor, "prende extraordinariamente attenção de toda a classe" e ainda "desenvolve muitissimo as faculdades para os futuros cálculos" (Guimarães, 1909, p. 25). Assim, para Guimarães, tais materiais representavam o mais moderno e adequado recurso didático para o ensino de Aritmética no ensino primário.

Por sua vez, os livros didáticos simbolizam o velho e ultrapassado ensino tradicional, baseado na memorização e repetição. Para a Pedagogia Moderna era necessário modificar completamente os métodos seguidos nas escolas primárias, os quais empregavam os livros no lugar das coisas. Desejava-se o contrário: que o livro e o texto se retirassem ante a coisa, ante a realidade. A educação escolar deveria seguir as indicações da natureza, ou seja, as crianças deveriam ser educadas tal como a natureza educou o gênero humano: intuitivamente, empiricamente, repetindo em suas vidas os estágios de desenvolvimento de toda a humanidade (Teive, 2014). Dessa forma, nos grupos escolares, as coisas deveriam tomar o lugar dos livros e, para isso, determinou-se a proibição do "uso dos alumnos decorarem compendios ou mesmo apontamentos fornecidos ou dictados pelos professores" (Santa Catarina, 1914b, p. 18).

Neste sentido, para a matéria de Aritmética, não foi estabelecido um compêndio didático para utilização pelos alunos em sala, assim como na maioria das matérias escolares. Os únicos livros adotados e aprovados para os grupos escolares foram a Cartilha analítica, de Arnaldo Barreto, o livro de Leitura preparatória, de Francisco Vianna, uma séria graduada de leitura do mesmo autor e, para o quarto e último ano da escola primária, um livro de leitura de cunho cívico-patriótico denominado Minha pátria, de Pinto e Silva (Santa Catarina, 1911c).

No entanto, apesar de tal proibição, o inspetor Orestes Guimarães realizou, em Parecer sobre a adopção de obras didacticas, ${ }^{6}$ uma seleção das obras mais adequadas para compor as bibliotecas dos grupos escolares. Destacamos que os livros de Aritmética indicados foram: Arithmetica escolar: livro do mestre, Ramon Roca Dordal; Calculo mental, Brasilicus; Calculo arithmetica, Alfredo Soares; Soluções e respostas de

\footnotetext{
${ }^{5}$ O professor Orestes Guimarães foi responsável por reorganizar o Colégio Municipal de Joinville no ano de 1907. O eficiente trabalho desenvolvido neste período abriu caminho para sua futura atuação, como reformador do sistema de educação catarinense em 1910 (Fiori, 1991).

6 O professor paulista Orestes Guimarães, no cargo de Inspetor Geral da Instrução Pública de Santa Catarina, realizou um Parecer sobre a adopção de obras didacticas visando à uniformização das obras nas escolas públicas catarinenses. Suas indicações foram inspiradas nas obras aprovadas para as escolas de São Paulo, conforme afirma Costa (2014, p. 58), "idealizado primeiro em São Paulo, o parecer paulista foi substancialmente utilizado para escrita do parecer catarinense". 
arithmetica e Systema metrico (curso elementar e médio), U. Auvert. Dessa forma podemos inferir que, mesmo que estes livros não fossem utilizados pelos alunos, os professores tinham contato com estes materiais para o preparo de suas aulas.

Das obras anteriormente citadas tivemos acesso ao livro de Dordal, que é destinado a orientar os professores na condução das práticas pedagógicas, alicerçadas pelo método intuitivo. Nesta perspectiva, o livro adquire uma função diferenciada de instrução: assume papel de material essencial para o professor na elaboração de suas atividades, em oposição à função desempenhada anteriormente de detentor principal das lições a serem memorizadas pelos alunos. Essa característica, livro para uso docente ou manual didático, não é uma inovação destes autores, mas era uma tendência pouco difundida na época e que começou a se proliferar, segundo Valdemarin (1998), frente a tantas proposições inovadoras advindas da nova metodologia de ensino.

Além dos livros disponibilizados nas bibliotecas, os professores dos grupos escolares, formados na Escola Normal Catarinense, tiveram acesso ao compêndio Arithmetica progressiva - curso superior de autoria de Antônio Trajano. Esta obra inovou o ensino de Aritmética relacionando-a com a solução de problemas e o método intuitivo. De acordo com os estudos de Teive (2008), o livro de Trajano foi utilizado na escola normal até a década de 1930 .

\section{Considerações finais}

A análise realizada neste estudo buscou compreender a inclusão e organização da matéria Aritmética nos programas de ensino dos grupos escolares de Santa Catarina durante os primeiros anos da reforma Orestes Guimarães. Sendo assim, a investigação empreendida nestas fontes documentais nos permitiu delinear um panorama educacional em que a matriz pedagógica do ensino intuitivo, alicerçada pela organização graduada dos estudos seriados, caracterizou uma nova formatação para o ensino da Aritmética.

Além disso, percebemos uma representação do passado do ensino primário catarinense profundamente negativa, que considerava velho e antiquado tudo o que a ele se relacionava. Para romper com o ensino abstrato e pouco utilitário da pedagogia tradicional, a reforma Orestes Guimarães buscou na reforma do método de ensino a renovação da instrução pública no Estado.

A presença do método intuitivo no ensino de Aritmética revelou um novo pensamento pedagógico que contraria as disposições anteriores do ensino em que se privilegiava a memorização dos saberes. Os materiais didáticos prescritos para subsidiar as aulas de Aritmética nos grupos escolares catarinenses foram os objetos concretos, como os tornos de sapateiro, e os quadros de Parker. Este último merece destaque por se constituir em único impresso indicado para utilização dos professores no ensino de Aritmética, já que os compêndios foram proibidos para uso em sala.

A influência paulista nas prescrições para a matéria de Aritmética se fizeram constantemente presentes. O parecer que estabeleceu os livros didáticos adotados nas bibliotecas dos grupos escolares, por exemplo, foi inspirado no parecer realizado alguns anos antes em São Paulo. Dessa forma, o parecer catarinense apresenta muitas similaridades com o paulista, inclusive quanto aos títulos de livros de Aritmética. 
Por fim, a indicação de obras didáticas para a composição de bibliotecas escolares por Orestes Guimarães sugere, ainda, que pode ter havido uma aproximação do corpo docente com outros impressos didáticos, além dos quadros de Parker.

\section{Referências}

ARAUJO, José Carlos Souza. Os grupos escolares em Minas Gerais como expressão de uma política pública: uma perspectiva histórica. In: VIDAL, Diana Gonçalves (org.). Grupos escolares: cultura escolar primária e escolarização da infância no Brasil (18931971). Campinas: Mercado de Letras, 2006, p. 193-213.

BENCOSTTA, Marcus Levy. Desfiles patrióticos: memória e cultura cívicas dos grupos escolares de Curitiba. In: VIDAL, Diana Gonçalves (org.). Grupos escolares: cultura escolar primária e escolarização da infância no Brasil (1893-1971). Campinas: Mercado de Letras, 2006, p. 299-321.

CHERVEL, André. História das disciplinas escolares: reflexões sobre um campo de pesquisa. Teoria \& Educação. Porto Alegre, v. 2, 1990, p. 177-229.

COSTA, David Antonio da. Alguns elementos da história da educação matemática no estado de Santa Catarina, Brasil, no século 20: a aritmética nos grupos escolares. Hist. Educ. (Online), v.18, n. 44, 2014, p. 27-43.

FARIA FILHO, Luciano Mendes de. Dos pardieiros aos palácios: forma e cultura escolares em Belo Horizonte (1906/1918). São Paulo: USP, 1996. 362f. Tese (doutorado em Educação). Faculdade de Educação, Universidade de São Paulo.

FIORI, Neide Almeida. Aspectos da evolução do ensino público: ensino público e política de assimilação cultural no Estado de Santa Catarina nos períodos imperial e republicano. Florianópolis: UFSC, 1991.

GASPAR DA SILVA, Vera Lucia. Vitrines da República: os grupos escolares em Santa Catarina (1889-1930). In: VIDAL, Diana Gonçalves (org.). Grupos escolares: cultura escolar primária e escolarização da infância no Brasil (1893-1971). Campinas: Mercado de Letras, 2006, p. 341-376.

GUIMARÃES, Orestes de Oliveira. Relatório do Collégio Municipal de 1907 a 1909 apresentado ao Exmo. Sr. Superintendente Municipal de Joinville pelo diretor em commissão - Orestes de Oliveira Guimarães. Joinville, 1909. Disponível em <https://repositorio.ufsc.br/handle/123456789/101193>. Acesso em 18 out. 2015.

GUIMARÃES, Orestes de Oliveira. Parecer sobre a adoção de obras didáticas. 1911. Florianópolis, 1911. Disponível em <https://repositorio.ufsc.br/handle/ 123456789/101130>. Acesso em 18 out. 2015.

HOELLER, Solange Aparecida de Oliveira; SOUZA, Gizele de. Programas e métodos de ensino para a infância catarinense nas reformas educacionais de 1910/1913. Revista Linhas, Florianópolis: Udesc, v. 10, n. 1, 2009, p. 73-87.

JULIA, Dominique. A cultura escolar como objeto histórico. Revista Brasileira de História da Educação, Campinas: SBHE, n. 1, p. 9-43, 2001.

LEME DA SILVA, Maria Célia; VALENTE, Wagner Rodrigues. Aritmética e geometria nos anos iniciais: o passado sempre presente. Revista Educação em Questão, Natal: UFRN, v. 47, n. 33,2013 , p. $178-206$. 
LOPES, Antonio de Pádua Carvalho. Das escolas reunidas ao grupo escolar: a escola como repartição pública de verdade. In: VIDAL, Diana Gonçalves (org.). Grupos escolares: cultura escolar primária e escolarização da infância no Brasil (1893-1971). Campinas: Mercado de Letras, 2006, p. 81-107.

NÓBREGA, Paulo de. Grupos escolares: modernização do ensino e poder oligárquico. In: DALLABRIDA, Norberto. Mosaico de escolas: modos de educação em Santa Catarina na primeira república. Florianópolis: Cidade Futura, 2003, p. 253-280.

RAMOS, Vidal José de Oliveira. Mensagem apresentada ao Congresso Representativo, em 24 de julho de 1913. Florianópolis: Gab. Typ. D’O Dia, 1913.

RAMOS, Vidal José de Oliveira Synopse apresentada pelo Coronel Vidal José de Oliveira Ramos, em 20 de junho de 1914. Florianópolis, 1914. Acervo Apesc. Disponível em <https://repositorio.ufsc.br/handle/123456789/126120>. Acesso em 18 out. 2015.

SÁ, Elizabeth Figueiredo. O florescer de uma cultura escolar no ensino público matogrossense. In: VIDAL, Diana Gonçalves (org.). Grupos escolares: cultura escolar primária e escolarização da infância no Brasil (1893-1971). Campinas: Mercado de Letras, 2006, p. 215-232.

SANTA CATARINA. Lei n. 846, 11 out. 1910. Florianópolis, 1910. Acervo: Apesc. Disponível em <https://repositorio.ufsc.br/xmlui/handle/123456789/101114>. Acesso em: 18 out. 2015.

SANTA CATARINA. Programa dos grupos escolares e das escolas isoladas do estado de Santa Catarina. Decreto n. 587, 22 abril 1911. Joinville: Typ. Boehm, 1911a. Acervo Apesc. Disponível em <https://repositorio.ufsc.br/handle/123456789/99196>. Acesso em 18 out. 2015.

SANTA CATARINA. Regimento Interno dos grupos escolares. Decreto n. 588, 22 abr. 1911. Gab. Typ. D'<0 dia>. Florianópolis, 1911b. Acervo: Apesc. Disponível em <https://repositorio.ufsc.br/xmlui/handle/123456789/122502>. Acesso em 18 out. 2015.

SANTA CATARINA. Decreto n. 596, 07 jul. 1911. Florianópolis, 1911c. Acervo da Apesc. Disponível em <https://repositorio.ufsc.br/handle/123456789/123490>. Acesso em 18 out. 2015.

SANTA CATARINA. Lei n. 967, de 22 de ago. 1913. Florianópolis, 1914. Acervo Apesc. Disponível em <https://repositorio.ufsc.br/handle/123456789/101117>. Acesso em 18 out. 2015.

SANTA CATARINA. Programa dos grupos escolares e das escolas isoladas do estado de Santa Catarina. Decreto n. 796, 2 maio 1914. Joinville: Typ. Boehm, 1914a. Acervo Apesc. Disponível em <https://repositorio.ufsc.br/handle/123456789/105101>. Acesso em 18 out. 2015.

SANTA CATARINA. Regimento interno dos grupos escolares. Decreto $n$. 795, 2 maio 1914. 1914b. Acervo Apesc. Disponível em <https://repositorio.ufsc.br/handle/ 123456789/105191>. Acesso em 18 out. 2015.

SOUZA, Rosa Fátima. Inovação educacional no século XIX: a construção do currículo da escola primária no Brasil. Cadernos Cedes, n. 51, nov. 2000, p. 9-28.

TEIVE, Gladys Mary Ghizoni. Uma vez normalista sempre normalista: cultura escolar e produção de um habitus pedagógico. Florianópolis: Insular, 2008. 
TEIVE, Gladys Mary Ghizoni. Pedagogia moderna no Brasil: primeiras discussões e experiências práticas (final do século XIX - início do XX). Revista Mexicana de Historia de la Educación, v. 2, n. 4, 2014, p. 153-172.

TEIVE, Gladys Mary Ghizoni; DALLABRIDA, Noberto. A escola da república: os grupos escolares e a modernização do ensino primário em Santa Catarina (1911-1918). Campinas: Mercado de Letras, 2011.

VALDEMARIN, Vera Teresa. Método intuitivo: os sentidos como janelas e portas que se abrem para um mundo interpretado. In: SOUZA, Rosa Fátima de; VALDEMARIN, Vera Teresa; ALMEIDA, Jane Soares de. O legado educacional do século XIX. Araraquara: Unesp, 1998, p. 63-105.

VALENTE, Wagner Rodrigues. A matemática na escola de primeiras letras: o que devem saber os meninos nos primeiros tempos de império. CONGRESSO LUSO-BRASILEIRO DE HISTÓRIA DA EDUCAÇÃO, 6, 2006. Anais... Uberlândia: UFU, p. 3367-3374.

DAVID ANTONIO DA COSTA é doutor em Educação Matemática pela Pontifícia Universidade Católica de São Paulo e professor no Centro de Ciências da Educação e no Programa de Pós-Graduação em Educação Cientifica e Tecnológica da Universidade Federal de Santa Catarina.

Endereço: Rua Douglas Seabra Levier, 163 - Bloco B/208 - 88040-410 Florianópolis - SC - Brasil.

E-mail: david.costa@ufsc.br.

THUYSA SCHLICHTING DE SOUZA é mestre em Educação Científica e Tecnológica pela Universidade Federal de Santa Catarina.

Endereço: Rua Antônio Eleutério Vieira, 50 - Bloco A/505 - 88025-380 Florianópolis - SC - Brasil.

E-mail: thuysads@gmail.com.

Recebido em 19 de outubro de 2015.

Aceito em 25 de janeiro de 2016. 